\title{
Improved cider fermentation performance and quality with newly generated Saccharomyces cerevisiae $\times$ Saccharomyces eubayanus hybrids
}

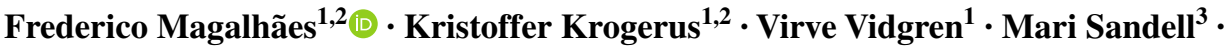 \\ Brian Gibson ${ }^{1}$
}

Received: 4 January 2017 / Accepted: 16 April 2017 / Published online: 27 April 2017

(c) The Author(s) 2017. This article is an open access publication

\begin{abstract}
Yeast cryotolerance may be advantageous for cider making, where low temperatures are usually employed. Here, we crossed the cryotolerant $S$. eubayanus with a $S$. cerevisiae wine strain and assessed the suitability of the hybrids for low-temperature cider fermentation. All strains fermented the juice to 5\% ABV, but at different rates; hybrid strains outperformed $S$. cerevisiae, which was sensitive to low temperatures. The best hybrid fermented similarly to $S$. eubayanus. S. eubayanus produced sulphurous off flavours which masked a high concentration of fruity ester notes. This phenotype was absent in the hybrid strains, resulting in distinctly fruitier ciders. Aroma was assessed by an independent consumer panel, which rated the hybrid ciders as identical to the wine strain cider. Both were significantly more pleasant than the $S$. eubayanus cider. Interspecific hybridization can apparently be used effectively to improve low-temperature fermentation performance without compromising product quality.
\end{abstract}

Keywords Saccharomyces eubayanus · Cider . Hybridization · Cryotolerance

Electronic supplementary material The online version of this article (doi:10.1007/s10295-017-1947-7) contains supplementary material, which is available to authorized users.

Frederico Magalhães

frederico.magalhaes@vtt.fi

1 VTT Technical Research Centre of Finland Ltd, Tietotie 2, P.O. Box 1000, 02044 Espoo, Finland

2 Department of Biotechnology and Chemical Technology, School of Chemical Technology, Aalto University, Kemistintie 1, Aalto, P.O. Box 16100, 00076 Espoo, Finland

3 Functional Foods Forum 20014 University of Turku, Itäinen Pitkäkatu 4 A, Turku, Finland

\section{Introduction}

The temperature employed in alcoholic beverages fermentations impacts the sensorial properties of the final product. There are several reasons why cold fermentations (i.e., lower than $15{ }^{\circ} \mathrm{C}$ ) are preferred over warm fermentations. In brewing, these conditions allow for the production of the clean and fresh tasting lager beer, which has contributed to the global popularity of this beer style [15]. Contrarily, in white wine making, low temperature actually improves the aromatic profile of the wine $[9,10,40]$. Compounds like ethyl esters associated with fruit notes and freshness tend to be produced and maintained at higher concentrations in white wines fermented at low temperatures [40]. The reduced evaporation of volatile compounds in the cold must also be taken into consideration. Other than the sensorial properties, the use of low temperatures also reduces the likelihood of contamination by spoilage organisms, potentially obviating the use of $\mathrm{SO}_{2}$. It is, however, necessary to have a yeast strain that is able to survive and retain metabolic activity at these temperatures if fermentation is to proceed efficiently.

Naturally cold-tolerant strains like Saccharomyces kudriavzevii, S. uvarum or S. eubayanus could potentially be used for low-temperature fermentations, but tend to have higher ethanol sensitivity than $S$. cerevisiae and may, therefore, be less suitable for alcoholic fermentation [6]. It is not uncommon, however, to find hybrids of $S$. cerevisiae and a cold-tolerant Saccharomyces species associated with alcoholic fermentations. From the bestknown case of the lager yeast $S$. cerevisiae $\times S$. eubayanus hybrids $[15,26]$, to hybrids involving $S$. cerevisiae, $S$. uvarum and/or $S$. kudriavzevii in cider fermentations $[18,35,42]$. 
Since the discovery of S. eubayanus in Patagonia [31] there has been an interest in recreating the hybridization event and generating new lager strains for brewing applications $[22,24,25,37]$. The discovery has also inspired new approaches to facilitate the selection of artificial hybrid strains [2]. Lager yeast hybrids have inherited the superior fermentation performance from their $S$. cerevisiae parent and the cold tolerance from S. eubayanus. This has resulted in strains that have superior phenotypic properties relative to their parents, a phenomenon called heterosis [15].

Cold tolerance seems the main phenotypic contribution of $S$. eubayanus to the natural and artificial lager yeast strains [22, 25, 37], but the presence of an additional high-affinity fructose transporter, Fsy1, could provide hybrids with improved ability to reduce the critical accumulation of fructose in the later phases of the wine and cider fermentations [32]. Fructose represents the larger portion of fermentable sugars in apple juice, being usually present in concentration two times higher than glucose [56].

Countries like France, Spain, Ireland and Slovenia have a strong cider culture and this is traditionally produced with naturally occurring indigenous yeast at temperatures ranging from 12 to $20{ }^{\circ} \mathrm{C}$ [41]. In the initial stages of cider production species from the genus Candida, Pichia, Hansenula, Hanseniaspora and Metschnikowia predominate, having a strong influence in the aromatic complexity of the cider [12, 39, 41, 55]. The alcoholic fermentation, however, is carried by Saccharomyces species [54].

There has been an increased interest in cider production recently, particularly in North America but also in Eastern European countries without a tradition for cider consumption. In 2015 alone, cider production, for example, grew by $106 \%$ in Poland. This accelerated production was most likely a result of a search for an alternative use for apples after the Russian ban on apple importing from Poland combined with record production levels and decrease in excise duties [17]. The increased popularity of cider can also be attributed to consumer tastes changing towards less-bitter drinks, with the addition of being gluten-free and lower in alcohol than wine.

In this work, we describe the generation of new interspecific hybrids between an $S$. cerevisiae wine strain and $S$. eubayanus type strain and characterised the potential of these hybrids for cider fermentations. The ciders were analysed for their aromatic properties and were also evaluated by a consumer panel.

\section{Materials and methods}

\section{Strains}

Yeast strains used in this work are listed in Table 1. Parental strains include $S$. eubayanus type strain (CBS 12357) deposited at VTT culture collection as C-12902 and $S$. cerevisiae 59A [3], a haploid isolate of the industrial wine strain Lalvin EC1118. The six hybrid strains generated by crossing the two parental strains are deposited at VTT Culture Collection as VTT C-16962 to VTT C-16967. Abbreviated codes (C962-C967) are use in the text.

\section{Hybrid generation}

Prior to hybridization, natural lysine auxotrophic mutants of $S$. cerevisiae 59A were selected based on their ability to grow on $\alpha$-aminoadipic acid-containing agar [57]. Lack of growth in minimal selection medium confirmed the auxotrophy [25].

Hybrids between S. cerevisiae 59A lys- and S. eubayanus C902 were generated by rare mating as described in Ref. [25]. A fresh colony of each parent was used to inoculate YPD cultures that were grown overnight at $25^{\circ} \mathrm{C}$. The cultures were centrifuged at $5000 \times g$ for $5 \mathrm{~min}$ and the cells were washed and re-suspended in sterile $\mathrm{H}_{2} \mathrm{O}$ to a concentration of $10 \mathrm{~g} \mathrm{~L}^{-1}$. In a sterile $2 \mathrm{~mL}$ Eppendorf tube

Table 1 List of strains used in this study

\begin{tabular}{lllll}
\hline Strain codes & Species & Ploidy & MtDNA & Additional information \\
\hline 59A & S. cerevisiae & $1.01 n$ & & Haploid derivative of industrial wine strain Lalvin EC1118 [3] \\
VTT C-12902 (C902) & S. eubayanus & $2.07 n$ & & S. eubayanus type strain; CBS12357 [31] \\
VTT C-16962 (C962) & Interspecies hybrid & $2.29 n$ & S. cerevisiae & 59A $\times$ C902 hybrid \\
VTT C-16963 (C963) & Interspecies hybrid & $2.17 n$ & S. cerevisiae & 59A $\times$ C902 hybrid \\
VTT C-16964 (C964) & Interspecies hybrid & $2.07 n$ & S. cerevisiae & 59A $\times$ C902 hybrid \\
VTT C-16965 (C965) & Interspecies hybrid & $2.38 n$ & n.d. & 59A $\times$ C902 hybrid \\
VTT C-16966 (C966) & Interspecies hybrid & $2.12 n$ & n.d & 59A $\times$ C902 hybrid \\
VTT C-16967 (C967) & Interspecies hybrid & $2.25 n$ & n.d. & 59A $\times$ C902 hybrid \\
\hline
\end{tabular}

n.d.- not detected 
$100 \mu \mathrm{L}$ of each suspension were added followed by $1 \mathrm{~mL}$ of YPD medium. The procedure was performed in triplicate. The tubes were vortexed and incubated statically for 5 days at $25{ }^{\circ} \mathrm{C}$. Finally, the suspension was washed and re-suspended in $500 \mu \mathrm{L}$ of starvation medium $(0.1 \%$ yeast extract and $0.1 \%$ glucose) and incubated for $2 \mathrm{~h}$ at room temperature.

For selection of prototrophic hybrid cells, the suspension was vortexed and $100 \mu \mathrm{L}$ were added per minimal selection agar (without lysine) plate. These plates were incubated at $37{ }^{\circ} \mathrm{C}$ (an inhibitory temperature for S. eubayanus) and the hybrids were selected based on the restoration of prototrophy and ability to grow at $37^{\circ} \mathrm{C}$.

\section{Confirmation of hybrid status}

Colonies were checked for their hybrid status by rDNAPCR amplification using the primers ITS1 (5'-TCCGTAGGTGAACCTGCGG- $\left.3^{\prime}\right)$ and ITS4 (5'-TCCTCCGCTTATTGATATGC-3'), followed by a digestion using HaeIII (New England Biolabs, Ipswich, MA, USA) [25]. Hybrids can be identified by having the ITS regions of both parents and thus the restriction profile appears as a combination of the parental profiles. Briefly, S. cerevisiae yields a 4 band pattern $(320,225,180,140 \mathrm{bp})$, S. eubayanus 3 bands $(490,225,140 \mathrm{bp})$ and interspecific hybrids 5 bands (490, 320, 225, 180 and $140 \mathrm{bp})$. In addition, strain specific primers were used to confirm the presence of DNA from both parents, MEX67 for S. cerevisiae 59A, ScerF2 (5'-GCGCTTTACATTCAGATCCCGAG-3') and ScerR2 (5'-TAAGTTGGTTGTCAGCAAGATTG-3'), and a putative maltose transporter for $S$. eubayanus C902, SeubF4 (5'-CGATGAAGGGCTTATCCTCACTG-3') and SeubF5 (5'-CGAGATGGTGTGCTTCGCC-3').

\section{Ploidy determination by FACS}

The DNA content was determined by flow cytometry essentially as described by Haase and Reed [21]. The parental strain $S$. cerevisiae 59A forms aggregates that impair an accurate measurement of the ploidy and so a strains deleted on AMN1 gene was used [34]. Cells were grown overnight in YPD medium (1\% yeast extract, $2 \%$ peptone, $2 \%$ glucose), and approximately $1 \times 10^{7}$ cells were washed with $1 \mathrm{~mL}$ of $50 \mathrm{mM}$ citrate buffer. Cells were fixed with cold $70 \%$ ethanol and incubated at room temperature for $1 \mathrm{~h}$. Cells were then washed with $50 \mathrm{mM}$ citrate buffer, resuspended in $50 \mathrm{mM}$ citrate buffer containing $0.25 \mathrm{mg} \mathrm{mL}^{-1}$ RNAse A and incubated overnight at $37^{\circ} \mathrm{C}$. $1 \mathrm{mg} \mathrm{mL}^{-1}$ of Proteinase $\mathrm{K}$ was then added, and cells were incubated for $1 \mathrm{~h}$ at $50{ }^{\circ} \mathrm{C}$. Cells were then stained with SYTOX Green ( $2 \mu \mathrm{M}$; Life Technologies, USA), and their DNA content was determined using a FACSAria cytometer
(Becton-Dickinson). DNA contents were calculated by comparing fluorescence intensities with those of $S$. cerevisiae haploid (CEN.PK113-1A) and diploid (CEN.PK) reference strains. Measurements were performed on duplicate independent yeast cultures, and 100,000 events were collected per sample during flow cytometry.

\section{Origin of mitochondria}

The origin of the mitochondria inherited by the hybrids was assessed by sequencing of the COX2 gene. The gene was amplified by PCR using the following primers: COX2 (forward): GGTATTTTAGAATTACATGA and COX2 (reverse): ATTTATTGTTCRTTTAATCA as described in Ref. [7]. PCR products were purified with QIAquick PCR purification kit (Qiagen) and sequenced by GATC-Biotech using the same primers. Gene sequences were aligned using MUltiple Sequence Comparison by Log-Expectation (MUSCLE; http://www.ebi.ac.uk/Tools/msa/muscle/). The functionality of mitochondria was assessed by plating a fresh colony onto a YP plate containing 3\% (w/v) glycerol as the sole carbon source.

\section{Temperature tolerance}

The range of growing temperatures was determined by drop test. A culture of each strain was grown overnight in YPD medium. The $\mathrm{OD}_{600 \mathrm{~nm}}$ of each culture was adjusted to 0.5 and three consecutive tenfold dilutions were made $(0.05,0.005$ and 0.0005$) .5 \mu \mathrm{L}$ of each dilution were spotted in several plates and these were incubated at temperatures of $7,10,20,28$ and $37{ }^{\circ} \mathrm{C}$ and allowed to grow for 2 days at 28 and $37^{\circ} \mathrm{C}, 3$ days at $20^{\circ} \mathrm{C}, 5$ days at $12{ }^{\circ} \mathrm{C}$ and 7 days at $4{ }^{\circ} \mathrm{C}$.

\section{Fructose and glucose uptake}

For fructose and glucose uptake measurement, the yeast strains were grown at $20{ }^{\circ} \mathrm{C}$ in liquid $\mathrm{YP}$ medium containing glucose $(2 \% \mathrm{w} / \mathrm{v})$ to an $\mathrm{OD}_{600 \mathrm{~nm}}$ between 4 and 8 . The cells were harvested by centrifugation $(10 \mathrm{~min}, 5000 \mathrm{rpm}$, $0{ }^{\circ} \mathrm{C}$ ), washed with ice-cold water and $0.1 \mathrm{M}$ tartrate-Tris (pH 4.2) and re-suspended in the same buffer to a concentration of $200 \mathrm{mg}$ fresh yeast $\mathrm{mL}^{-1}$. Zero-trans rates of $\left[\mathrm{U}-{ }^{14} \mathrm{C}\right]$-fructose and $\left[\mathrm{U}_{-}{ }^{14} \mathrm{C}\right]$-glucose uptake at $20{ }^{\circ} \mathrm{C}$ were determined with $5 \mathrm{mM}$ of substrate with $10 \mathrm{~s}$ incubation time [33]. Two incubation times were tested to ensure linearity with respect to time with $\mathrm{t} 2$ corresponding to at least $90 \%$ of t1 value. [U- ${ }^{14} \mathrm{C}$ ]-Fructose (ART0329) was from American Radiolabelled Chemicals (St. Louis, MO, USA) and $\left[\mathrm{U}_{-}{ }^{14} \mathrm{C}\right]$-glucose (CFB 96) was from Amersham Biosciences (Buckinghamshire, UK). 


\section{Apple juice fermentation}

Apple juice fermentation was carried out with a similar setup as previously described for brewer's wort [16, 47]. A concentrated mixture of apple and pear juice (74\%; Finlandia cider, Senson Oy, Lahti, Finland) was used as substrate for cider fermentations. The concentrate contains sulphur dioxide, ammonium phosphate and the sweetener acesulphame K. Juice was diluted to a concentration of approximately $11^{\circ}$ Brix $\left(64 \mathrm{~g} \mathrm{~L}^{-1}\right.$ fructose and $32 \mathrm{~g} \mathrm{~L}^{-1}$ glucose). $1.5 \mathrm{~L}$ of $11^{\circ}$ Brix juice was fermented with selected strains in stainless steel cylindroconical vessels (so-called tall tubes) with dimensions of $6 \mathrm{~cm}$ internal diameter $\times 100 \mathrm{~cm}$ height (two litres) at a pitching rate of $3 \mathrm{~g}$ of fresh yeast $\mathrm{L}^{-1}$. Starting cultures were prepared by inoculating a fresh colony in $50 \mathrm{~mL} \mathrm{YPD}$ and grown for $24 \mathrm{~h}$ at $25^{\circ} \mathrm{C}$, $150 \mathrm{rpm}$. The culture was then diluted in $500 \mathrm{~mL} 11^{\circ}$ Brix apple juice to an initial OD of 0.1 and grown for 2 days. The fermentations were carried out at 10 and $20{ }^{\circ} \mathrm{C}$ until no change in the residual extract was observed for $24 \mathrm{~h}$.

Samples were withdrawn daily, centrifuged at $9000 \mathrm{rpm}$ for $10 \mathrm{~min}$ at $1{ }^{\circ} \mathrm{C}$ and the pellet was washed with water, weighed, re-suspended in water and used for yeast analyses. Dry yeast masses were determined by drying the washed yeast slurry overnight at $105{ }^{\circ} \mathrm{C}$ in a pre-weighed porcelain crucible. Specific gravity, alcohol level and $\mathrm{pH}$ were determined from the centrifuged and degassed fermentation samples using an Anton Paar density meter DMA $5000 \mathrm{M}$ with Alcolyzer Beer ME and pH ME modules (Anton Paar GmbH, Austria).

Concentration of fermentable sugars (glucose and fructose) was measured by HPLC using a waters 2695 separation module and waters system interface module liquid chromatograph coupled with a waters 2414 differential refractometer (Waters Co., Milford, MA, USA). An Aminex HPX-87H organic acid analysis column $(300 \times 7.8 \mathrm{~mm}$, Bio-Rad) was equilibrated with $5 \mathrm{mM} \mathrm{H}_{2} \mathrm{SO}_{4}$ (Titrisol, Merck, Germany) in water at $55{ }^{\circ} \mathrm{C}$ and samples were eluted with $5 \mathrm{mM} \mathrm{H}_{2} \mathrm{SO}_{4}$ in water at a $0.3 \mathrm{ml} \mathrm{min}^{-1}$ flow rate.

\section{Quantification of volatile compounds}

Fourteen yeast-derived volatile compounds were determined by headspace gas chromatography with flame ionisation detector (HSGC-FID) analysis. Four-millilitre samples were filtered $(0.45 \mu \mathrm{m})$ and incubated at $60{ }^{\circ} \mathrm{C}$ for $30 \mathrm{~min}$, and then $1 \mathrm{~mL}$ of gas phase was injected (split mode; $225{ }^{\circ} \mathrm{C}$; split flow of $30 \mathrm{~mL} \mathrm{~min}^{-1}$ ) into a gas chromatograph equipped with an FID detector and headspace autosampler (Agilent 7890 Series; Palo Alto, CA, USA). Analytes were separated on a HP-5 capillary column $(50 \mathrm{~m} \times 320 \mu \mathrm{m} \times 1.05 \mu \mathrm{m}$ column; Agilent, USA). The carrier gas was helium (constant flow of $1.4 \mathrm{~mL} \mathrm{~min}{ }^{-1}$ ). The temperature programme was $50{ }^{\circ} \mathrm{C}$ for $3 \mathrm{~min}, 10^{\circ} \mathrm{C}$ $\min ^{-1}-100{ }^{\circ} \mathrm{C}, 5{ }^{\circ} \mathrm{C} \min ^{-1}-140{ }^{\circ} \mathrm{C}, 15{ }^{\circ} \mathrm{C} \min ^{-1}-260{ }^{\circ} \mathrm{C}$ and then isothermal for $1 \mathrm{~min}$. Compounds were identified by comparison with authentic standards and were quantified using standard curves. 1-Butanol was used as internal standard.

Twelve sulphur volatile compounds (SVC) in the ciders produced at $20{ }^{\circ} \mathrm{C}$ were quantified by Campden BRI (Nutfield, Surrey, UK) by purge-and-trap linked to GC with chemiluminescence detection. The sample was purged with helium into a Tekmar-Dohrmann sample concentrator then the trapped volatiles were desorbed and injected into the GC coupled with a sulphur-specific Sievers chemiluminescence detector. Sulphur volatiles were individually calibrated against reference standards.

\section{Consumer study}

To assess the quality of the ciders produced by the hybrids relative to the parents, a panel of volunteer consumers rated the pleasantness of aroma on a scale of 1 (dislike extremely) to 9 (like extremely) of the ciders produced at $20{ }^{\circ} \mathrm{C}$. The panel consisted of 45 women and 13 men between 18 and 65 years old from the southwest of Finland. Data were collected using Compusense Cloud (Compusense Inc. Ontario, Canada). The study was conducted at the sensory laboratory of the Functional Foods Forum (ISO 8589), University of Turku.

\section{Data analysis}

Statistical analysis was performed with R (http://www. rproject.org/; v3.3.0) using one-way ANOVA and Tukey test. Visualisation of data in heat-maps was done with the package ggplot based on $z$ scores. The $z$ scores $(z)$ were calculated as $z=(x-\mu) / \sigma$, where $x$ is the concentration of an aroma compound in a particular cider sample, $\mu$ is the mean concentration of that aroma compound in all ciders, and $\sigma$ is the standard deviation of concentration of that aroma compound in all ciders.

\section{Results}

\section{Confirmation of hybrid status, ploidy and mitochondria determination}

The colonies growing in selective conditions were regarded as potential hybrids and were screened through ITS PCR followed by digestion with HaeIII and species specific PCR. The 5 band digestion pattern (Fig. S1a) and the 2 band amplification (Fig. S1b) confirmed the presence of 
genetic material from the two different species. Additionally, the presence of chromosomes from both parents can be seen in the karyotype (Fig. S1c).

The ploidy measurements confirmed that $S$. cerevisiae 59A is haploid (1.01n) and S. eubayanus diploid (2.07n) (Fig. S2, Table 1). The hybrids were found to be roughly diploid but with small variation in DNA content between them, ranging from $2.07 n$ to $2.38 n$ (Fig. S2, Table 1). Sequencing of $C O X 2$ gene revealed that hybrids C962, C963 and C964 contain S. cerevisiae mitochondrial DNA (Table 1; Fig S3). PCR using DNA from the strains C965, C966 and C967 did not yield any product in several attempts, suggesting defective or absent mitochondria. The functionality of the mitochondria was evaluated by testing the ability to grow in medium YP containing glycerol as carbon source. This assay confirmed the inability of hybrids C965-C967 to grow on non-fermentable carbon sources indicating the absence of functional mitochondria (Fig. S4).

\section{Temperature tolerance and uptake of the hexoses glucose and fructose}

Growth temperature and sugar uptake are the major factors affecting the fermentation rate. We tested the range of growth temperatures by drop test and the uptake of radiolabelled glucose and fructose.

The strains reacted differently to incubation temperatures (Fig. 1). S. cerevisiae 59A preferred the highest temperatures $\left(>28{ }^{\circ} \mathrm{C}\right)$ while $S$. eubayanus grew well up to $28{ }^{\circ} \mathrm{C}$ but not further with particularly good ability to grow at $4{ }^{\circ} \mathrm{C}$. Hybrid strains grew in the whole range of temperatures tested, however, with marked differences. Strains C964 and C966 displayed the highest versatility (Fig. 1).

The uptake of the sugars present in apple and pear juice, glucose and fructose, showed that $S$. cerevisiae parent had a similarly low ability to take up both of the sugars (Fig. 2). In contrast, S. eubayanus C902 had the highest uptake activity for both sugars, and the uptake of glucose was more than two times higher than that of fructose. The ability of the hybrids to take up sugars varied from 10.5 to 38.4

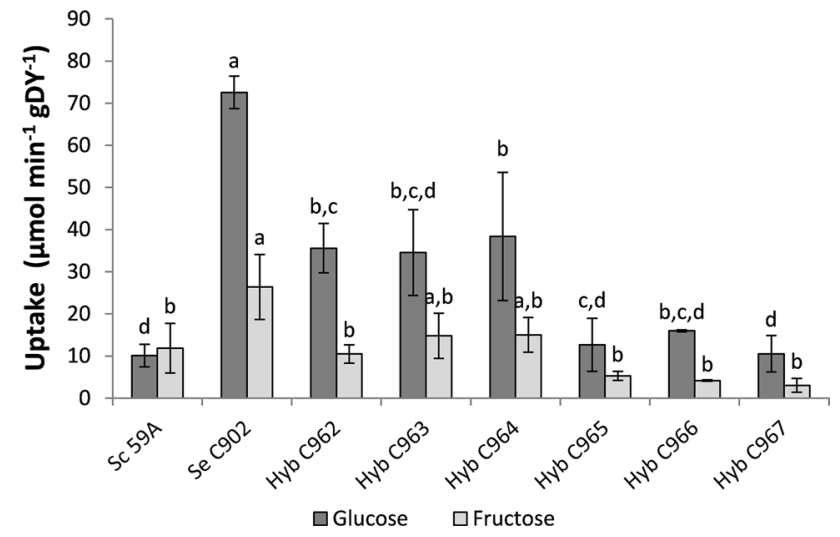

Fig. 2 Zero-trans rates of glucose and fructose uptake activity $\left(\mu \mathrm{mol} \mathrm{min}{ }^{-1} \mathrm{~g}^{-1} \mathrm{DY}\right)$ of the strains in study, measured at $20{ }^{\circ} \mathrm{C} .59 \mathrm{~A}$ and $\mathrm{C} 902$ are $S$. cerevisiae and S. eubayanus parents, respectively and C962-C967 are hybrid strains. Values are means of three independent assays; error bars represent standard deviation; different letters $(a-d)$ represent significant differences between strains for a given sugar as determined by one-way ANOVA and Tukey test

and 3.0 to $15.0 \mu \mathrm{mol} \mathrm{min}^{-1} \mathrm{~g} \mathrm{DY}^{-1}$ for glucose and fructose, respectively, with ratios between glucose and fructose uptake higher than 2. At this stage, three hybrid strains were chosen for further characterization based on uptake activity, C967 with the lowest activity, C962 with intermediate activity and C964 with the highest activity.

\section{Fermentation in cider-making conditions}

All strains were able to completely ferment the juice to about 5\% ABV (Alcohol by volume), although at different rates. In accordance with the higher uptake rates of both glucose and fructose, at $20{ }^{\circ} \mathrm{C} \mathrm{S}$. eubayanus and C964 are able to complete the fermentation after $72 \mathrm{~h}$ (Fig. 3a). The hybrids C962 and C967 follow with a slower rate, fermenting all the available sugars at $96 \mathrm{~h}$, while the $S$. cerevisiae 59A had the worst performance (Fig. 3a). By reducing the fermentation temperature to $10{ }^{\circ} \mathrm{C}$ the cold-tolerant nature of $S$. eubayanus becomes more evident. The fermentation time was considerably longer at the lower temperature and
Fig. 1 Drop test for assessment of the range of growth temperatures of the hybrids (C962-C967) relative to the parents (59A, C902). Plates were grown for 2 days at 28 and $37^{\circ} \mathrm{C}, 3$ days at $20{ }^{\circ} \mathrm{C}, 5$ days at $12{ }^{\circ} \mathrm{C}$ and 7 days at $4{ }^{\circ} \mathrm{C}$

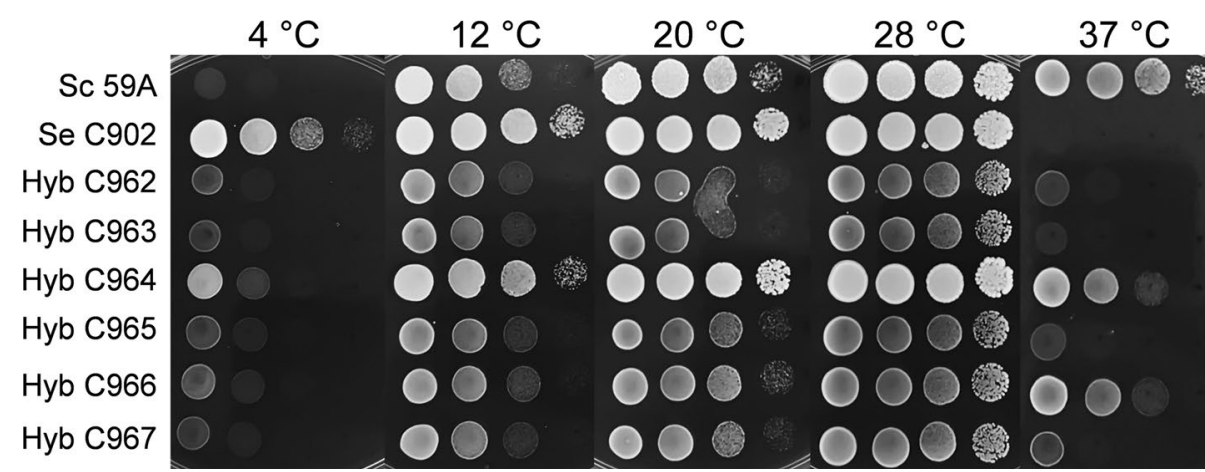



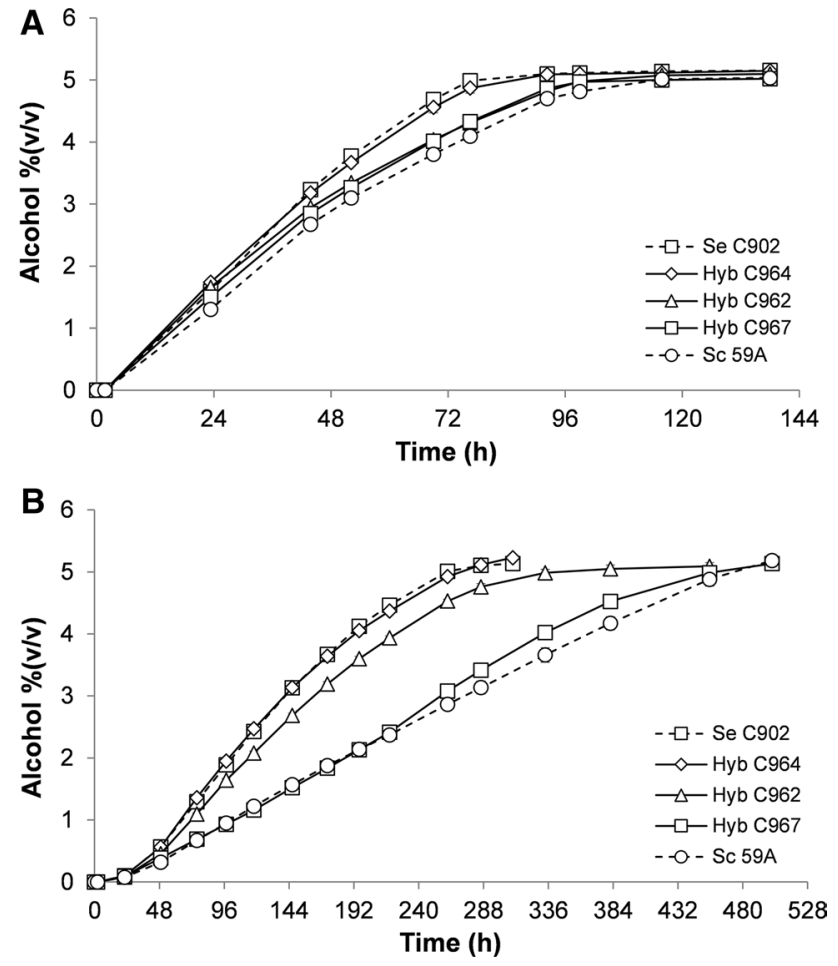

Fig. 3 Fermentation (\% ABV) of $11^{\circ} \mathrm{P}$ apple juice at $20{ }^{\circ} \mathrm{C}$ (a) and $10{ }^{\circ} \mathrm{C}(\mathbf{b})$. Values are means from two independent fermentations and error bars where visible represent the range

the differences between the strains were clearer. The hybrid C964 and S. eubayanus C902 were the fastest fermenters, completing after $288 \mathrm{~h}$ (Fig. 3b). The hybrid C962 here performed quite differently from C967, consuming all sugars in $384 \mathrm{~h}$ (Fig. 3b). The hybrid C967 and S. cerevisiae 59A took more than $480 \mathrm{~h}$ to ferment the juice (Fig. 3b). The variable sugar uptake rates of the hybrid strains (Fig. 2) also correlate well with the consumption of glucose and fructose (Fig. S3). At both temperatures tested, hybridization with $S$. eubayanus C902 resulted in an improvement of the fermentation performance in relation to the parent $S$. cerevisiae 59A.

\section{Cider quality assessment}

In the cider industry, improvement of fermentation performance is only advantageous if it does not come at the expense of product quality. With that in mind, we measured the concentration of esters and higher alcohols in the final ciders as well as unpleasant sulphuric volatile compounds. This was followed by an evaluation of the pleasantness of aroma of the produced ciders by a consumer panel. Aromatic profiles of the ciders produced at both temperatures were clearly different. A fermenting temperature of $20^{\circ} \mathrm{C}$ resulted in an average of three times greater production of volatile compounds than at $10{ }^{\circ} \mathrm{C}$, and 3 times lower production of acetaldehyde (Fig. 4; Table S1). Considering variations between strains, the hybrid $\mathrm{C} 967$ plotted closely to the $S$. cerevisiae parent, producing a similar aroma profile and generally producing the lowest amounts of esters and higher alcohols (Fig. 4; Table S1). Similarly, the aroma production by strain $\mathrm{C} 962$ at $10{ }^{\circ} \mathrm{C}$ is closer to that of $\mathrm{C} 964$ while at $20{ }^{\circ} \mathrm{C}$ it is closer to C967 and 59A. S. eubayanus C902 in general produced high levels of aroma compounds, particularly the rose-like 2-phenylethanol. The hybrid strain C964 once again performed similarly to S. eubayanus, producing very aromatic cider relative to the 59A $S$. cerevisiae strain (Fig. 4; Table S1). S. eubayanus C902 has shown to be a good fermenting strain and also has the ability to produce reasonably high amounts of desirable aromatic compounds but has the disadvantage of producing significant quantities of Sulphur Volatile Compounds (SVCs) that have low aroma perception thresholds and can mask the cider's fruity/floral notes even when present in very low concentrations (Table 2). Of the twelve sulphur compounds measured, four were at concentrations below the detection limit (diethyl sulphide, hydrogen sulphide, n-propane thiol and t-butyl mercaptan) and four compounds were detected at concentrations below the odour threshold (dimethyl disulphide, ethyl thioacetate, ethylene sulphide and methyl thioacetate) and thus are unlikely to have a direct impact on the final product. The cider produced with $S$. eubayanus C902 contained diethyl disulphide and methanethiol at concentrations close to the odour threshold of 0.4 and $1.5 \mu \mathrm{g} \mathrm{L} \mathrm{L}^{-1}$, respectively. Ethanethiol was found to be present at more than two times the odour threshold in the ciders produced by $S$. eubayanus. These compounds are characterised by a strong unpleasant rotten cabbage and onion aroma. Interestingly, these seem to be absent or much reduced in the hybrid strains, as in the $S$. cerevisiae parent.

To evaluate how the combination of the different measured compounds affects perceived quality of the ciders, a panel of 58 consumers was asked to rate the ciders based on the pleasantness of aroma. The results clearly show that the ciders produced by all the hybrids are as pleasant as the cider made with $S$. cerevisiae 59A, while being significantly more pleasant that the cider produced by $S$. eubayanus (Fig. 5). This confirms that not only was it possible to significantly reduce the production of SVCs through interspecific hybridization as the analytical data shows, but that this was also reduced to below sensory detection levels in the final product.

\section{Discussion}

The use of hybrid yeast involving S. eubayanus is still limited to lager beer brewing. The lager yeast are, however, a group with rather low genetic and phenotypic diversity 
Fig. 4 Heat-map representative of relative concentrations of aroma compounds in the ciders. The heat-map was generated based on $Z$ scores; strains with different letters ( $a$ to $i$ ) for the same compound are significantly different; significance letters are ordered alphabetically from the highest to lowest concentration of each aroma compound

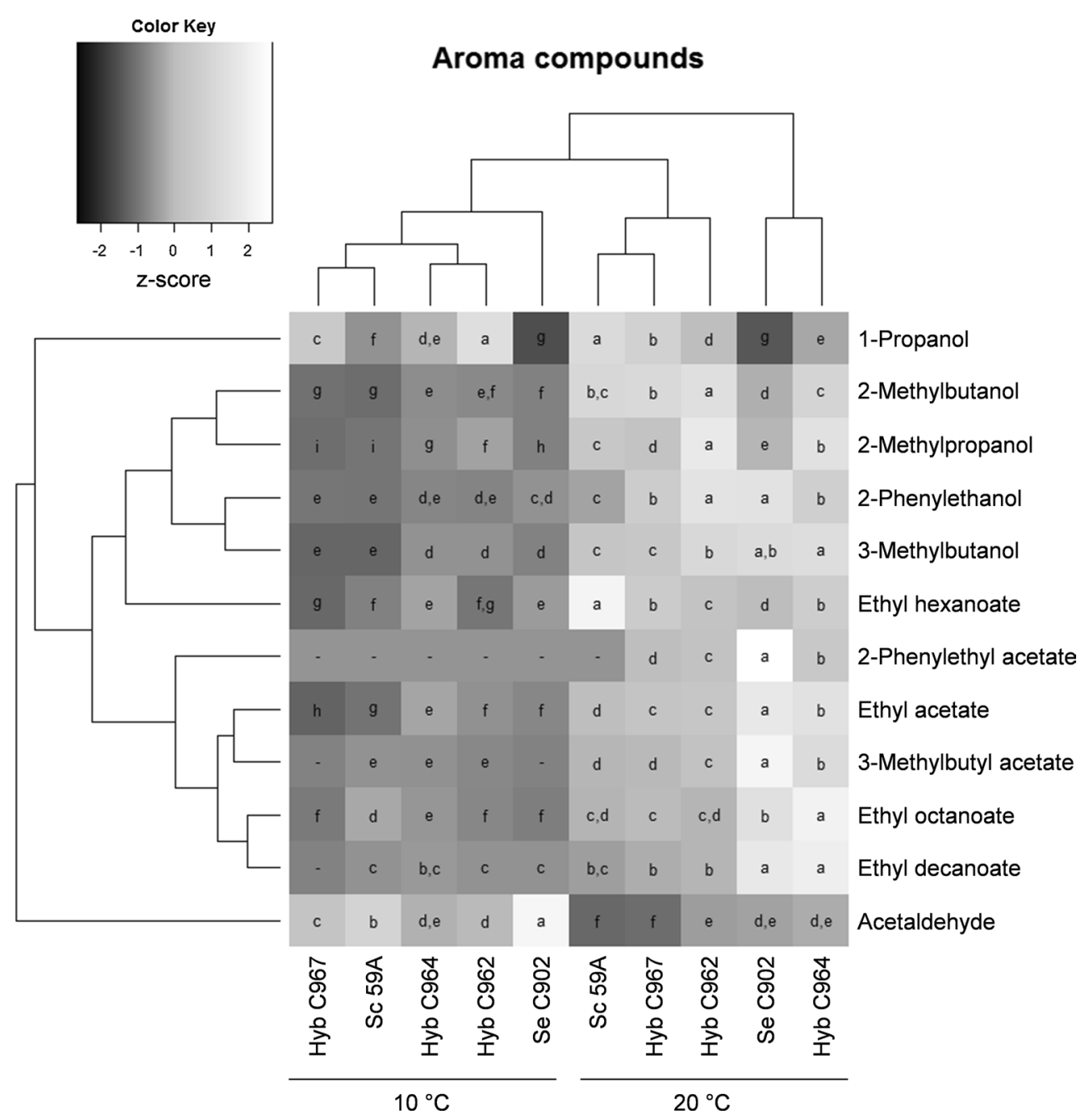

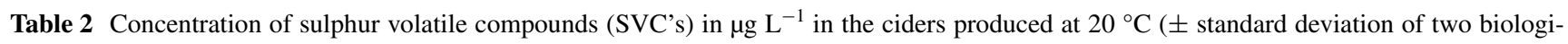
cal replicates)

\begin{tabular}{lllllll}
\hline & Odour threshold & Sc 59A & Se C902 & Hyb C962 & Hyb C964 & Hyb C967 \\
\hline Diethyl disulphide & $0.4^{\mathrm{a}}[8]$ & n.d. & $0.44 \pm 0.16$ & n.d. & n.d. & n.d. \\
Dimethyl disulphide & $20-45^{\mathrm{c}}[38]$ & $0.35 \pm 0.07$ & $0.35 \pm 0.35$ & $0.55 \pm 0.07$ & $0.65 \pm 0.35$ & $0.35 \pm 0.07$ \\
Dimethyl trisulphide & $0.2^{\mathrm{c}}[20]$ & n.d. & n.d. & $0.10 \pm 0.14$ & $0.15 \pm 0.21$ & n.d. \\
Ethanethiol & $1.1^{\mathrm{c}}[38]$ & n.d. & $2.34 \pm 0.74$ & $0.12 \pm 0.16$ & n.d. & n.d. \\
Ethyl thioacetate & $10^{\mathrm{a}}[8]$ & n.d. & $1.15 \pm 0.35$ & n.d. & n.d. & n.d. \\
Ethylene sulphide & & $0.15 \pm 0.07$ & $0.05 \pm 0.07$ & $0.30 \pm 0.00$ & $0.20 \pm 0.00$ & $0.30 \pm 0.14$ \\
Methanethiol & $1.5^{\mathrm{b}}$ & $0.20 \pm 0.00$ & $1.15 \pm 0.50$ & $1.10 \pm 0.07$ & $0.65 \pm 0.07$ & $0.30 \pm 0.14$ \\
Methyl thioacetate & $50^{\mathrm{a}}[8]$ & n.d. & $1.55 \pm 0.50$ & $1.50 \pm 0.14$ & $0.90 \pm 0.14$ & $0.30 \pm 0.42$ \\
\hline
\end{tabular}

n.d. not detected, concentration below detection limit

a in beer

$\mathrm{b}$ in cider

c in wine

[26]. The limited aroma spectrum of lager strains is desirable for lager beers, where a clean aroma is generally preferred [26]. Ciders, however, benefit from a more complex profile. Wine strains represent a more diverse group of strains and therefore a more interesting alternative for cider making. After crossing a wine strain with S. eubayanus, 


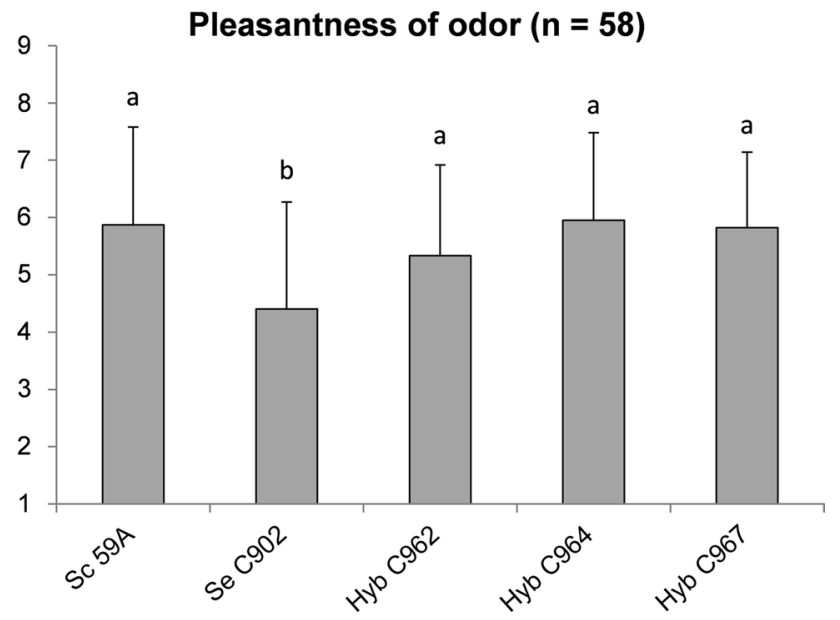

Fig. 5 Pleasantness of the cider aroma as evaluated by a consumer panel. Ciders were rated from extremely unpleasant (1) to extremely pleasant (9). Error bars represent standard deviation; different letters $(a, b)$ represent significant differences

hybrid strains were expected to inherit the more pleasant aroma profile of the former and the reportedly high tolerance to low temperatures of the latter [31].

We obtained diploid hybrid strains with variable performance in apple juice, with the best strain performing similarly to $S$. eubayanus and producing comparable amounts of aroma compounds but with the advantage of producing SVCs at concentrations under the detection level.

Hybrids generated by rare mating often contain the complete DNA of both parents [19, 24]; this was, however, not the case here as the hybrids were diploid rather than triploid. This may be either caused by the high sporulation capacity of S. eubayanus [48] that resulted in a spore of C902 mating with S. cerevisiae 59A, or by loss of chromosomes post-hybridization due to chromosome instability and even incompatibility. Examples of the latter are the chromosome III from $S$. cerevisiae that has high loss frequency [28] and the chromosome XII from S. bayanus being partially incompatible with the $S$. cerevisiae genome [30]. This phenomenon seems to be strain and species specific $[28,32]$. S. cerevisiae $\times S$. uvarum and $S$. cerevisiae $\times S$. kudriavzevii hybrids show different rates of chromosome loss with hybrids involving $S$. kudriavzevii being more unstable [32]. The chromosomes from the non$S$. cerevisiae parent tend to be have higher loss frequency $[43,44]$. However, the ploidy of the $S$. cerevisiae $\times S$. eubayanus hybrids generated in this study was measured shortly after purification and confirmation in the hybrid state and, thus, such rearrangements of the hybrid genome are unlikely to have had the chance to occur. The alternative, i.e., fusion of a haploid cell and haploid spore may therefore be more plausible. The diploid state may explain why only single parent transgression in fermentation was observed. Recent studies on artificial hybrids with different ploidies have shown a direct and positive relationship between DNA content and fermentation rate [24].

The phenotypic variations among hybrid strain were visible already in the range of growth temperatures. An ability to grow at high temperatures $\left(37^{\circ} \mathrm{C}\right)$, a property not possessed by $S$. eubayanus $\mathrm{C} 902$, was expected as this was one of the selection factors. However, at the lower range of $4-12{ }^{\circ} \mathrm{C}$, the strain $\mathrm{C} 964$ was clearly different to the others. The mechanisms of cold tolerance of $S$. eubayanus are still unclear [26]. One possible explanation is that the genome of S. eubayanus may be more dominant in this hybrid strain which also shows a similar fermentation profile; however, that is not yet known. A higher proportion of S. eubayanus genetic material in lager yeast hybrids appears to relate with the cold tolerance of these strains [16].

The non-Mendelian nature of mitochondria inheritance can also influence the phenotypic properties of new hybrid strains. The hybrids described in this study either contain S. cerevisiae mitochondria (C962-C964) or no mitochondria was found (C965-C967). The hybrids containing $S$. cerevisiae mitochondria showed superior hexose transport, but the advantage to fermentation performance was only observed at low temperature fermentation $\left(10^{\circ} \mathrm{C}\right)$, possibly due to the reduced influence of mitochondria on fermentative behaviour [1]. However, S. cerevisiae $\times S$. uvarum hybrids that retain the $S$. cerevisiae mitochondrial genome have lower expression of genes related to hexose transport and glycolysis/fermentation pathways [51]. Nevertheless, the same study also suggests that the inheritance of mitochondrial DNA is strain specific and therefore hybrids obtained from repeated crosses with the same parental strains will retain the same mtDNA [51]. This seems to be true for lager strains, where only S. eubayanus type mitochondria were found independently of the strain group $[13,45]$. When hybrids are generated artificially, the origin of mitochondrial DNA varies even when using the same parental strains [24]. A more recent study showed that, in addition to the strain background, environmental conditions also influence the origin of the mtDNA retained in interspecific hybrids [23]. This is also, however, unlikely to explain the differences observed between the hybrids generated in this work, since these were maintained in similar conditions post-hybridization and during hybrid isolation. The most likely explanation for the loss of mitochondria may be that these 3 hybrids (C965-C967) initially contained $S$. eubayanus mitochondria, but during the hybrid isolation process the mitochondria were lost due to the high temperatures employed $\left(37^{\circ} \mathrm{C}\right)$. At this stage, the hybrid genomes are unstable and such temperature conditions may have induced the loss of S. eubayanus mitochondria, considering $37{ }^{\circ} \mathrm{C}$ is a restrictive temperature for $S$. eubayanus. Nonpermissive temperatures have been shown to restrict the 
transmission of mitochondria in $S$. cerevisiae strains with mutations in $M D M 1$ and $M D M 2$ genes [36]. These results suggest that there is still work to do to understand which factors influence the inheritance and the retention of functional mitochondria in interspecies hybrids.

The sugar uptake kinetics of S. eubayanus C902 are superior to those of $S$. cerevisiae 59A and, while the hybrids show lower uptake rates than $S$. eubayanus, these are still generally more efficient than $S$. cerevisiae in transporting glucose and fructose and this is reflected in the fermentation performance. The mechanism responsible is, however, not clear as little is known about hexose transport kinetics of $S$. eubayanus. In $S$. cerevisiae, HXT transporters are induced/repressed at varying concentrations of glucose, i.e., low affinity $H X T 1$ and $H X T 3$ are induced by high glucose levels while high-affinity HXT2 and HXT4-7 are induced by low glucose concentration and are essential at the end of fermentation together with FSY1 for fructose uptake [5, 14, 27, 29]. The latter gene is present in both parent strains and they share $78 \%$ similarity at the amino acid level [14]. The activity of Fsy1 symporter may be relevant for fructose scavenging in the later stages of fermentation as it is repressed at high fructose concentrations and induced by non-fermentable carbon sources such as ethanol [5, 14].

A disadvantage of using $S$. eubayanus for industrial fermentations is that it produces perceptible amounts of unpleasant sulphur volatiles. These completely masked the fruit and floral notes of the esters and higher alcohols, despite these being produced in much higher concentrations than in the $S$. cerevisiae fermentations. Unpleasant sulphur-like notes in beers produced with S. eubayanus strains have similarly been described before by Mertens and coworkers [37]. These were also apparently absent in hybrids produced with $S$. cerevisiae strains. Hybridization approaches for the removal of 4-vinylguaiacol (phenolic off-flavour) and $\mathrm{H}_{2} \mathrm{~S}$ have likewise been described $[11,53]$. The production of SVCs by $S$. eubayanus may be due to differential amino acid uptake. We noted that $S$. eubayanus C902 has greater nitrogen requirements than $S$. cerevisiae 59A and the hybrids (data not shown). In nitrogen-deficient conditions, the sulphate reduction sequence pathway is triggered to meet the yeast demand in cysteine and methionine, this results in accumulation of sulphide that is then released from the cells as $\mathrm{H}_{2} \mathrm{~S}$ [52]. $\mathrm{H}_{2} \mathrm{~S}$ reacts with ethanol or acetaldehyde to form ethanethiol which can be oxidised to diethyl disulphide [4, 46, 49] while methanethiol is formed by degradation of methionine [46].

Phenotypically, the hybrids display an interesting combination of the parental properties indicating potential for cider fermentation and possibly further applications. A wider range of temperatures permitting growth could be used to modulate the properties of the final product. It was shown that the aromatic profile is substantially different at fermentation temperatures of 10 and $20{ }^{\circ} \mathrm{C}$ in accordance with what is observed in brewing fermentations with natural lager hybrids [16]. Mass production of these yeast strains may also be facilitated as tolerance of temperatures as high as $37{ }^{\circ} \mathrm{C}$ is likely to facilitate production in the form of active dried yeast [50]. In addition, the high hexose uptake rates suggest that $S$. eubayanus and the hybrids could be advantageous for low-temperature fermentation of other sugar-rich substrates such as grape must.

Acknowledgements Eero Mattila is thanked for assistance in the VTT Pilot Brewery, and Aila Siltala for skilled technical assistance. Senson Oy is thanked for the donation of the fruit juice used in fermentations. We are greatful for Saila Mattila for conducting consumer test data collection in the FFF sensory laboratory, and also for volunteer consumers participating the study. This work was supported by the Academy of Finland (Academy Project 276480), the European Union's Seventh Framework Programme FP7/2007-2013/under REA Grant Agreement no. 606795 and Alfred Kordelin Foundation, Svenska Kulturfonden-The Swedish Cultural Foundation in Finland.

Open Access This article is distributed under the terms of the Creative Commons Attribution 4.0 International License (http://creativecommons.org/licenses/by/4.0/), which permits unrestricted use, distribution, and reproduction in any medium, provided you give appropriate credit to the original author(s) and the source, provide a link to the Creative Commons license, and indicate if changes were made.

\section{References}

1. Albertin W, Da Silva T, Rigoulet M, Salin B, Masneuf-Pomarede I, De Vienne D, Sicard D, Bely M, Marullo P (2013) The mitochondrial genome impacts respiration but not fermentation in interspecific Saccharomyces hybrids. PLoS One 8(9):e75121

2. Alexander WG, Peris D, Pfannenstiel BT, Opulente DA, Kuang M, Hittinger CT (2016) Efficient engineering of marker-free synthetic allotetraploids of Saccharomyces. Fungal Genet Biol 89:10-17

3. Ambroset C, Petit M, Brion C, Sanchez I, Delobel P, Guérin C, Chiapello H, Nicolas P, Bigey F, Dequin S, Blondin B (2011) Deciphering the molecular basis of wine yeast fermentation traits using a combined genetic and genomic approach. G3 (Bethesda) 1:263-281

4. Amerine MA, Berg HV, Kunkee RE, Ough CS, Singleton VL, Webb AD (1980) The technology of winemaking, 4th edn. AVI Technical Books, Westport

5. Anjos J, de Sousa HR, Roca C, Cássio F, Luttik M, Pronk JT, Salema-Oom M (1828) Gonçalves P (2013) Fsy1, the sole hexose-proton transporter characterized in Saccharomyces yeasts, exhibits a variable fructose: $\mathrm{h}+$ stoichiometry. BBA-Biomembranes 2:201-207

6. Arroyo-López FN, Salvadó Z, Tronchoni J, Guillamón JM, Barrio E, Querol A (2010) Susceptibility and resistance to ethanol in Saccharomyces strains isolated from wild and fermentative environments. Yeast 27(12):1005-1015

7. Badotti F, Vilaça ST, Arias A, Rosa CA, Barrio E (2014) Two interbreeding populations of Saccharomyces cerevisiae strains coexist in cachaça fermentations from Brazil. FEMS Yeast Res 14(2):289-301 
8. Baxter ED, Hughes PS (2001) Flavor determinants of beer quality. In: Beer: Quality, safety and nutritional aspects, 1st edn. R Soc Chem, Cambridge, pp 40-73

9. Beltran G, Novo M, Guillamón JM, Mas A, Rozès N (2008) Effect of fermentation temperature and culture media on the yeast lipid composition and wine volatile compounds. Int $\mathbf{J}$ Food Microbiol 121:169-177

10. Beltran G, Novo M, Leberre V, Sokol S, Labourdette D, Guillamon JM, Mas A, François J, Rozes N (2006) Integration of transcriptomic and metabolic analyses for understanding the global responses of low-temperature winemaking fermentations. FEMS Yeast Res 6(8):1167-1183

11. Bizaj E, Cordente A, Bellon J, Raspor P, Curtin C, Pretorius I (2012) A breeding strategy to harness flavour diversity of Saccharomyces interspecific hybrids and minimize hydrogen sulphide production. FEMS Yeast Res 12:456-465

12. Coton E, Coton M, Levert D, Casaregola S, Sohier D (2006) Yeast ecology in French cider and black olive natural fermentations. Int J Food Microbiol 108(1):130-135

13. Dunn B, Sherlock G (2008) Reconstruction of the genome origins and evolution of the hybrid lager yeast Saccharomyces pastorianus. Genome Res 18(10):1610-1623

14. Galeote V, Novo M, Salema-Oom M, Brion C, Valério E, Gonçalves P, Dequin S (2010) FSY1, a horizontally transferred gene in the Saccharomyces cerevisiae EC1118 wine yeast strain, encodes a high-affinity fructose/ $\mathrm{H}+$ symporter. Microbiology 156(12):3754-3761

15. Gibson B, Liti G (2015) Saccharomyces pastorianus: genomic insights inspiring innovation for industry. Yeast 32(1):17-27

16. Gibson BR, Storgårds E, Krogerus K, Vidgren V (2013) Comparative physiology and fermentation performance of Saaz and Frohberg lager yeast strains and the parental species Saccharomyces eubayanus. Yeast 30:255-266

17. Grebinskij G (2016) The booming eastern european cider market. Available via Euromonitor International. http://blog. euromonitor.com/2016/07/booming-eastern-european-cider-market.html Accessed 03 Oct 2016

18. Groth C, Hansen J, Piskur J (1999) A natural chimeric yeast containing genetic material from three species. Int J Syst Bacteriol 49(4):1933-1938

19. Gunge N, Nakatomi Y (1972) Genetic mechanisms of rare matings of the yeast Saccharomyces cerevisiae heterozygous for mating type. Genetics 70(1):41-58

20. Guth H (1997) Identification of character impact odorants of different white wine varieties. J Agr Food Chem 45(8):3022-3026

21. Haase SB, Reed SI (2002) Improved flow cytometric analysis of the budding yeast cell cycle. Cell Cycle 1(2):117-121

22. Hebly M, Brickwedde A, Bolat I, Driessen M, de Hulster E, van den Broek M, Pronk J, Geertman J, Daran J, Daran-Lapujade P (2015) S. cerevisiae $\times$ S. eubayanus interspecific hybrid, best of both worlds and beyond. FEMS Yeast Res 15:fov005

23. Hsu YY, Chou JY (2017) Environmental factors can influence mitochondrial inheritance in the Saccharomyces yeast hybrids. PLoS One 12(1):e0169953

24. Krogerus K, Arvas M, Chiara M, Magalhães F, Mattinen L, Oja M, Vidgren V, Yue JX, Liti G, Gibson B (2016) Ploidy influences the functional attributes of de novo lager yeast hybrids. Appl Microbiol Biotechnol 100(16):7203-7222

25. Krogerus K, Magalhães F, Vidgren V, Gibson B (2015) New lager yeast strains generated by interspecific hybridization. J Ind Microbiol Biotechnol 42(5):769-778

26. Krogerus K, Magalhães F, Vidgren V, Gibson B (2017) Novel brewing yeast hybrids: creation and application. Appl microbial biotechnol 101(1):65-78

27. Kruckeberg AL (1996) The hexose transporter family of Saccharomyces cerevisiae. Arch Microbiol 166:283-292
28. Kumaran R, Yang SY, Leu JY (2013) Characterization of chromosome stability in diploid, polyploid and hybrid yeast cells. PLoS One 8(7):e68094

29. Leandro MJ, Fonseca C, Gonçalves P (2009) Hexose and pentose transport in ascomycetous yeasts: an overview. FEMS Yeast Res 9(4):511-525

30. Lee HY, Chou JY, Cheong L, Chang NH, Yang SY, Jun-Yi Leu (2008) Incompatibility of nuclear and mitochondrial genomes causes hybrid sterility between two yeast species. Cell 135:1065-1073

31. Libkind D, Hittinger CT, Valério E, Gonçalves C, Dover J, Johnston M, Gonçalves P, Sampaio JP (2011) Microbe domestication and the identification of the wild genetic stock of lager-brewing yeast. Proc Natl Acad Sci 108(35):14539-14544

32. Lopandic K, Pfliegler WP, Tiefenbrunner W, Gangl H, Sipiczki M, Sterflinger K (2016) Genotypic and phenotypic evolution of yeast interspecies hybrids during high-sugar fermentation. Appl Microbiol Biotechnol 100(14):6331-6343

33. Lucero P, Penalver E, Moreno E, Lagunas R (1997) Moderate concentrations of ethanol inhibit endocytosis of the yeast maltose transporter. Appl Environ Microbiol 63(10):3831-3836

34. Marsit S, Mena A, Bigey F, Sauvage FX, Couloux A, Guy J, Legras JL, Barrio E, Dequin S, Galeote V (2015) Evolutionary advantage conferred by an eukaryote-to-eukaryote gene transfer event in wine yeasts. Mol Biol Evol 32(7):1695-1707

35. Masneuf I, Hansen J, Groth C, Piskur J, Dubourdieu D (1998) New hybrids between Saccharomyces sensu stricto yeast species found among wine and cider production strains. Appl Environ Microbiol 64(10):3887-3892

36. McConnell SJ, Stewart LC, Talin A, Yaffe MP (1990) Temperature-sensitive yeast mutants defective in mitochondrial inheritance. J Cell Biol 111(3):967-976

37. Mertens S, Steensels J, Saels V, de Rouck G, Aerts G, Verstrepen K (2015) A large set of newly created interspecific yeast hybrids increases aromatic diversity in lager beers. Appl Environ Microbiol 81:8202-8214

38. Mestres M, Busto O, Guasch J (2000) Analysis of organic sulfur compounds in wine aroma. J Chromatogr A 881(1):569-581

39. Michel A, Bizeau C, Drilleau JF (1988) Flore levurienne présente dans les cidreries de l'ouest de la France. Sci Aliments 8(3):359-368

40. Molina AM, Swiegers JH, Varela C, Pretorius IS, Agosin E (2007) Influence of wine fermentation temperature on the synthesis of yeast-derived volatile aroma compounds. Appl Microbiol Biotechnol 77:675-687

41. Morrissey WF, Davenport B, Querol A, Dobson AD (2004) The role of indigenous yeasts in traditional Irish cider fermentations. J Appl Microbiol 97(3):647-655

42. Naumova ES, Naumov GI, Masneuf-Pomarède I, Aigle M, Dubourdieu D (2005) Molecular genetic study of introgression between Saccharomyces bayanus and S. cerevisiae. Yeast 22(14):1099-1115

43. Peris D, Belloch C, Lopandic K, Álvarez-Pérez JM, Querol A, Barrio E (2012) The molecular characterization of new types of Saccharomyces cerevisiae x S. kudriavzevii hybrid yeasts unveils a high genetic diversity. Yeast 29:81-91

44. Piotrowski JS, Nagarajan S, Kroll E, Stanbery A, Chiotti KE, Kruckeberg AL, Dunn B, Sherlock G, Rosenzweig F (2012) Different selective pressures lead to different genomic outcomes as newly-formed hybrid yeasts evolve. BMC Evol Biol 12:46

45. Rainieri S, Kodama Y, Nakao Y, Pulvirenti A, Giudici P (2008) The inheritance of mtDNA in lager brewing strains. FEMS Yeast Res 8(4):586-596

46. Rauhut D (1993) Yeasts-production of sulfur compounds. In: Fleet GH (ed) Wine microbiology and biotechnology. Harwood Academic, Chur, pp 183-223 
47. Rautio J, Londesborough J (2003) Maltose transport by brewer's yeasts in brewer's wort. J Inst Brew 109:251-261

48. Rodríguez ME, Pérez-Través L, Sangorrín MP, Barrio E, Lopes CA (2014) Saccharomyces eubayanus and Saccharomyces uvarum associated with the fermentation of Araucaria araucana seeds in Patagonia. FEMS Yeast Res 14(6):948-965

49. Sedighi M, Vahabzadeh F, Zamir SM, Naderifar A (2013) Ethanethiol degradation by Ralstonia eutropha. Biotechnol Bioprocess Eng 18(4):827-833

50. Serra A, Strehaiano P, Taillandier P (2005) Influence of temperature and $\mathrm{pH}$ on Saccharomyces bayanus var. uvarum growth; impact of a wine yeast interspecific hybridization on these parameters. Int J Food Microbiol 104(3):257-265

51. Solieri L, Antúnez O, Pérez-Ortín JE, Barrio E, Giudici P (2008) Mitochondrial inheritance and fermentative: oxidative balance in hybrids between Saccharomyces cerevisiae and Saccharomyces uvarum. Yeast 25(7):485-500

52. Swiegers JH, Pretorius IS (2007) Modulation of volatile sulfur compounds by wine yeast. Appl Microbiol Biotechnol 74(5):954-960
53. Tubb R, Searle B, Goodey A, Brown A (1981) Rare mating and transformation for construction of novel brewing yeasts. In: Proc 18th Congr Eur Brew Conv, pp 487-496

54. Valles BS, Bedriñana RP, García AG, Simón AQ (2007) A molecular genetic study of natural strains of Saccharomyces isolated from Asturian cider fermentations. J Appl Microbiol 103(4):778-786

55. Valles BS, Bedriñana RP, Tascón NF, Simón AQ, Madrera RR (2007) Yeast species associated with the spontaneous fermentation of cider. Food Microbiol 24(1):25-31

56. Ye M, Yue T, Yuan Y (2014) Effects of sequential mixed cultures of Wickerhamomyces anomalus and Saccharomyces cerevisiae on apple cider fermentation. FEMS Yeast Res 14(6):873-882

57. Zaret KS, Sherman F (1985) alpha-Aminoadipate as a primary nitrogen source for Saccharomyces cerevisiae mutants. J Bacteriol 162(2):579-583 